\title{
SUSTAINABLE DEVELOPMENT OF TOURISM IN THE EASTERN EUROPE: A CASE STUDY OF ROMANIA
}

\author{
Nedelea* and Babu P George**
}

Abstract
The strategies of sustainable development emphasize the
interdependence between the local and the global, between the already
developed countries and the ones following this course, underlining
the necessity of cooperation within economical, social and
environmental sections. Since, tourism plays an important role in the
improvement standards of living and rising people above the poverty
threshold, it has become a platform to transform the vicious circles of
misery, into virtuous circles towards productive transformation, welfare
and improvement of human capital. The complexity involved in
constructing knowledge in different contextual frames make the entire
debate on sustainable tourism extremely problematic, especially since
stake holding communities are spread across continents and cultures.
Many developing countries have found important to improve the linking
of tourism (forward and backward) with the other sectors of the
economy as one of the foundations of tourism development policies,
so as to capitalize on the benefits of the globalisation and

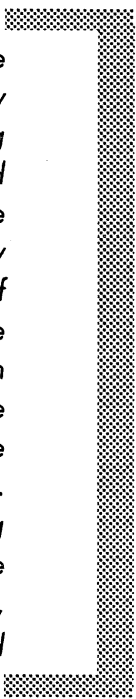

* Associate Professor, Ştefan cel Mare University, Romania

** Lecturer, Department of Tourism Studies, Pondicherry University, India 


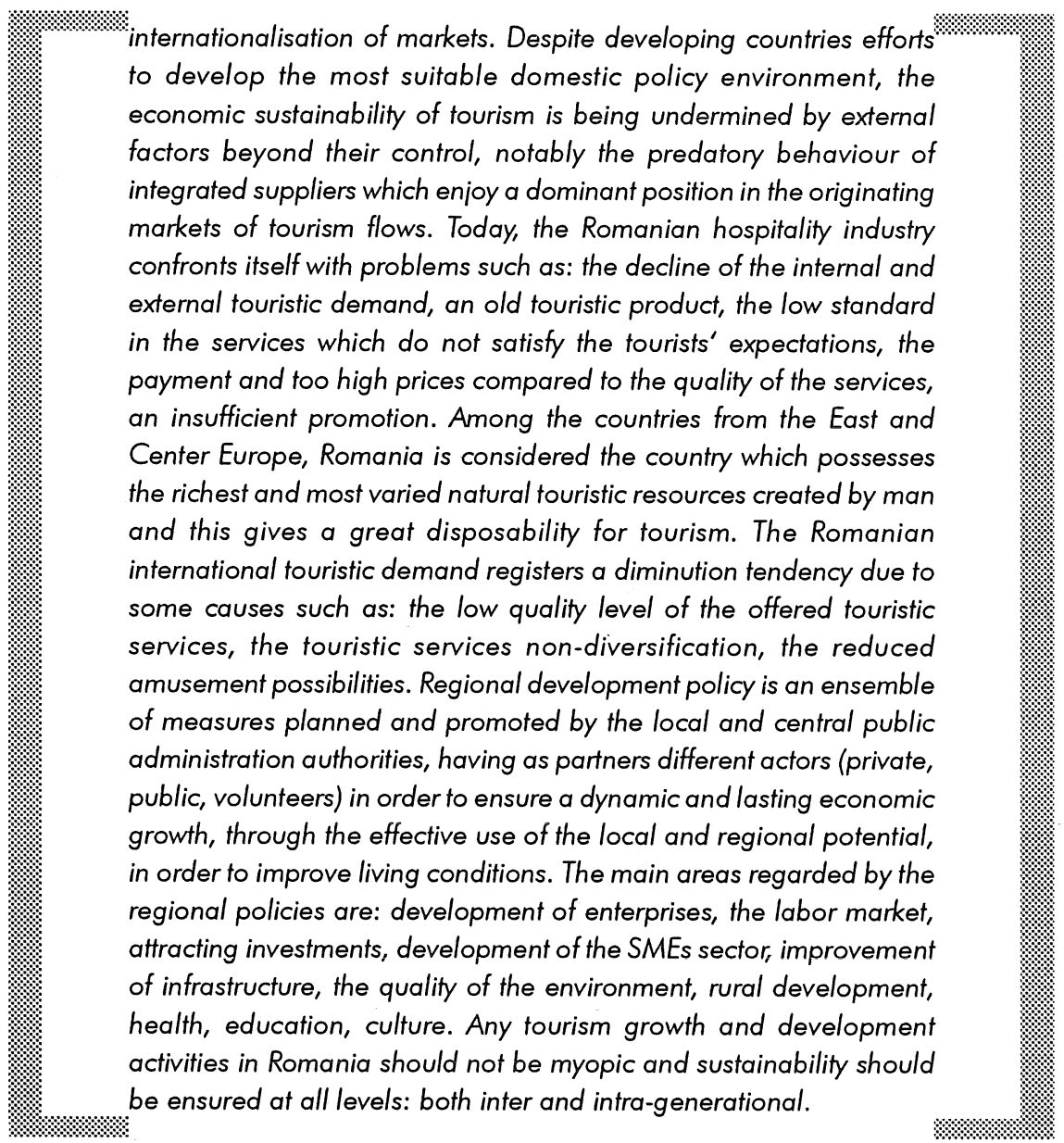

\section{Sustainable Development}

The concept of "sustainable development" indicates a major change in the approach of those problems concerning the human development by assuring a dynamic balance between the components of the natural capital and the socioeconomical systems. The strategies of suistainable development emphasize the interdependence between the local and the global, between the already developed countries and the ones following this course, underlining the necessity of cooperation within economical, social and environmental sections.

The tourism sector constitutes one of the most important sources of wealth of nations regardless of their level of development. For many developing countries, 
in particular the least developed countries (LDCs), small economies and islands states; tourism is probably the only economic sector, which provides concrete and quantified growing trading opportunities, and therefore, it is for them one of the fundamental pillars of their economic development. The negative impact of tourism, including its growing threat to the aims and practice of many conservations bodies was becoming better and more widely understood, in developed and developing countries alike.

"The green tourism" is especially used by those who have something to sell. In many people's mind it appears to mean the same as "rural tourism". Another popular term is "alternative tourism" wich conveys" some meaning of difference to mainstream practice, but doesn't include any sense of the activity itself, or what its principles may be. Another label that is sometimes used is "responsible tourism". This is to my mind has a rather sanctimonious and exclusive ring to it, and implies that all other tourism is totally irresponsible. The term "ecotourism" is a more meaningful one. It's most commonly applied to the type of holiday which enables tourists to have much more direct contact with nature than usual. Ecotourism generally means a visit to one of the more remote areas, where you can observe animals and birds in their natural habitat, examine the flora and fauna at first hand, or have direct, unmediated contact with a local community.

Since, tourism plays an important role in the improvement standards of living and rising people above the poverty threshold, it has become a platform to transform the vicious circles of misery, into virtuous circles towards productive transformation, welfare and improvement of human capital. Tourism not only provides material benefits it also brings cultural pride, a sense of ownership an control and through diversification, reduced vulnerability. Tourism should be assessed objectively against other opportunities, to overcome poverty in tourism destinations of developing countries.

Though, to maximize the benefits of tourism, the existing uneven distribution of benefits among nations that is threatening the economic, social, and environmental sustainability of tourism in many developing countries, have to be overcome. Yet, the 49 LDCs account today for only less than 1 percent of international tourist arrivals and an approximately 0.5 percent of international tourism receipts. This acute imbalance is being accentuated by the dependence of tourist destinations on external travel distribution networks, and the anticompetitive behavior of some tourism operators at worldwide scale. To a great extent, such a situation is responsible for the loss of potential remuneration of developing countries and in particular in LDCs. Mass tourism can destroy the environment, the economy, the host country and its people, even the tourists themseves. Sustainable development is the development that meets the needs of 
the present without compromising the ability of future generations to meet their own needs. The effect of our continuing misuse of the earth' resources, the part played by tourism in this process, the links between development and tourism are very important issues to be solved.

Tourism is at the present time the largest income generator of the world economy. Export revenue amounted to an estimated US $\$ 532$ billion, surpassing all the other international trade categories. International tourism totalled to US $\$ 441$ billion and the international transport of passengers US\$91 billion, which corresponded to 7.9 and 1.3 per cent respectively of worldwide exports of good and services. The proper functioning of the tourism economy is linked to that of many other related economic activities, which accounts for the importance of its economic, social and environmental sustainability. As a matter of fact, the extent to which the business operations of international tourism, backward and forward are linked with other sectors will determine the level of performance and profitability of tourism, the extent of multiplier and spill over effects, and the retention of value added, i.e. the leakage effect.

The sectors producing goods and services are linked backwards with tourism in catering for the needs of tourists and tourism operators, e.g. agriculture and food-processing industries, and other manufacturing industries providing furniture, construction materials and other articles required by tourism establishments. Similarly, many other services, such as transport, business services, financial services, professional services, construction design and engineering, environmental services, security services and government services, also ensure the efficient performance of tourism operators. Some of these sectors are also crucial for the proper linkage of tourism with foreign markets (forward linkages) because they constitute the platforms for "taking off" and for keeping the national tourism providers fully integrated with international tourism flows.

Many developing countries have found important to improve the linking of tourism (forward and backward) with the other sectors of the economy as one of the foundations of tourism development policies, so as to capitalize on the benefits of the globalisation and internationalisation of markets. Successful experiences of small economies, attest to the vital importance of the proper linkage of tourism with the rest of the economy, in their capacity of retaining value added, e.g., reducing leakages. Despite developing countries efforts to develop the most suitable domestic policy environment, the economic sustainability of tourism is being undermined by external factors beyond their control, notably the predatory behaviour of integrated suppliers which enjoy a dominant position in the originating markets of tourism flows. 
As a modality of international commerce, tourism involves not only inflows of foreign financial resources but also outflows, referred to herein as "leakages". When they exceed specific levels, these outflows can significantly neutralize the positive financial effect of international tourism. Leakage is the process whereby part of the foreign exchange earnings generated by tourism, rather than being retained by tourist-receiving countries, is either retained by tourist-generating countries or repatriated to them in the form of profits, income and royalty remittances, repayment of foreign loans, and imports of equipment, materials, capital and consumer goods to cater for the needs of international tourist and overseas promotional expenditures.

\section{Political Economy of Sustainable Tourism: Theory and Practice}

Tourism as an industry is increasing rapidly in developing countries. Due to the historical inequality in global trading relationships on the basis of core-periphery dependency, globalization and liberalized free trade, mainstream mass tourism reinforces the social and economic disadvantages of southern destinations. Hence, some view modern tourism as an extension of colonialism (Palmer, 1994).

Critics have, over the years, constructed a discourse of international tourism in terms dependency theory. Exploration, hunting, and trading dominated touristic purposes at least until the mid-nineteenth century (Chachage, 1999). Extractive as is the nature of such tourism, gains were made and directions of development controlled by the colonial powers and their agents. Such activities caused a heavy depletion of ecological resources in the colonies. Still, today, tourism remains the privilege of the few. WTO forecasts that only $7 \%$ of the world population will travel abroad by 2020 . Seen hidden in the development of modern day 'adventure tourism' and 'eco-tourism' is a drive to explore the 'exotic' (Poon, 1998). Even today, the mechanism and devices of control and access to tourist arrivals and the struggle between sending and host countries over retention of tourist expenditures are not fundamentally different. Despite possessing abundant resources for natural comparative advantage, developing countries and their tourism entities are subjected to intense cost and development pressures by their more developed business (country) partners (Hindley and Smith, 1994). In spite of all the romanticism, the reality is at the bottom line, tourism is a "business transaction, a commodity for sale in the world market." From a diverse number of points, the conventional wisdom that tourism is unambiguously good is problematic (Grassl, 1999). 
The issues of sustainability often lie in the competition between economic sectors for the scarce resources of land, water, energy, waste assimilation capacity, and human capital. Each stakeholder group has its own personal interest in this economic competition. For marketers, it is the desire to attract the eco-conscious postmodern traveler who will pay high sums for 'authentic,' 'unadulterated' experiences in the 'natural' settings. Non-governmental organizations and activist groups find in it great sources of funding. One of the often quoted reports prepared by the UN World Commission on Environment and Development (See Our Common Future, 1987") implicitly forwards the paradigm of the postindustrial market philosophy. It heralds what is, according to its authors, the "growth imperative" as a key to ensuring both intra- and inter-generational equity. Associatively, a white paper from the WTO, released in July 2002, wants to "encourage the rapid expansion of tourism in line with market capacity" through "progressive liberalization." Some opponents see these as legitimization exercises undertaken at the behest of the transnational corporations.

Worldview of the developed West tends to stress the "development" part of Sustainable Development, while the Eastern worldview in general attaches relatively more importance to the "sustainability" part, independent of whether such an approach leads to development or not in the strict material sense of the term. Tourism theoreticians, especially the sociological school, try to take a middle path in an attempt to be comprehensive. For them, sustainable tourism is that which is developed and maintained in a form such that it is viable over an indefinite period of time and does not degrade or alter the physical and human environment to an extent that it prohibits the successful development and well being of other activities and processes (Jafari, 2000). The confusion, according to some, lies in our failure to appreciate in total the diverse conceptions that different communities hold - worldviews that are gestalts (Clark, 1991) which effectively prohibit attempts to compound these conceptions (each of which are meaningful to at least the members of the espousing community) into a richer and more encompassing reality. Such an encompassing reality would be more agreeable to the ecological school than is the economic counterpart which tends to feel more at ease with its accurate, scientific, and well defined goals and quantitative methods by which to reach them. Adamant attitudes of some of these 'scientific' economists betray their intellectual inertia. They forget that market rationality is nothing but the collective understanding of our individual understanding of what market is- in no way graspable since one's understanding of the collective understanding becomes instantly his individual understanding below some still higher collective understanding leading to an endless repetition of the spiral. 
The material presented above is only to suggest that the complexity involved in constructing knowledge in different contextual frames make the entire debate on sustainable tourism extremely problematic, especially since stake holding communities are spread across continents and cultures.

\section{Development of the Romanian Sustainable Tourism}

Without any notable exceptions the Romanian specialists and the foreign ones agree upon the fact that the Romanian tourism potential could compete with the touristic supply of any other country in the world thus significantly contributing to the income growth. Let's remember that in the 60s Romania was a successful touristic destination especially due to the Black Sea. The regress started with the comunist national isolation. Its fall has not brought the supposed good changes and today the tourism Romanian industry is measured by a series of parametres which explain its peripheral position in international context.

The economic, social and political context of the period after 1990 has not been one that contributed to the Romanian tourism development. Today, the Romanian hospitality industry confronts itself with problems such as: the decline of the internal and external touristic demand, an old touristic product, the low standard in the services which do not satisfy the tourists' expectations, the payment and too high prices compared to the quality of the services, an insufficient promotion. Moreover after 1989 because of the population low income level a restructuration of the consumption priorities took place and this did not favour tourism.

Among the countries from the East and Center Europe, Romania is considered the country which possesses the richest and most varied natural touristic resources created by man and this gives a great disposability for tourism. The general secretary of the International Tourism Organization states that: Such a country which owns the Danube Delta, the Black Sea, The Bukovina monasteries could live and prosper from tourism only. Unfortunately, as a Horwath British firm specialized in consultancy has pointed out, Romania is for the foreign tourists "an expired touristic product, an inadequate offer for time spending, which reflects the lack of investment." Thus Romania has reached an expensive touristic destination.

The Romanian international touristic demand registers a diminuation tendency due to some causes such as: the low quality level of the offered touristic services, the touristic services non-diversification, the reduced amusement possibilities. 
The internal touristic demand registered a diminuation tendency caused by the low sales power of the population and a lack of correlation between the practised tax levels and the service qualities.

Some of the possible ways of tourism relaunching constitutes the elaboration of some efficient marketing strategies and politics starting from a marketing environment analysis. In order to conceive and promote a competitive Romanian touristic product the adoption of a quality rise strategy is essential. In Romania the Q Mark National Application Program was conceived. On the local market we notice the horizontal integration (concentration) phenomenon manifestation which is concretized in some hotel chains development.

\section{Issues of Regional Development}

Regional development is a new concept that aims at stimulating and diversifying economic activities, stimulating investments in the private sector, contributing to decreasing unemployment and, last but not least, a concept that would lead to an improvement in the living standards.

In order to apply the regional development strategy, eight development regions were set up, spreading throughout the whole territory of Romania. Each development region comprises several counties. Development regions are not territorial-administrative entities, do not have legal personality, being the result of an agreement between the county and the local boards.

Regional development policy is an ensemble of measures planned and promoted by the local and central public administration authorities, having as partners different actors (private, public, volunteers) in order to ensure a dynamic and lasting economic growth, through the effective use of the local and regional potential, in order to improve living conditions. The main areas regarded by the regional policies are: development of enterprises, the labor market, attracting investments, development of the SMEs sector, improvement of infrastructure, the quality of the environment, rural development, health, education, culture.

Rural development has a very distinct place within regional policies, and deals with the following aspects: removal/reduction of poverty in the rural areas; balancing of economic opportunities and social conditions between the urban and rural areas; stimulating local initiatives; safeguarding of the spiritual and cultural patrimony. The development region, constituted as a freewill association of neighbour counties represents the implementation and assessment framework 
of the regional development policy. The development region is not a territorialadministrative entity and does not have legal personality.

The main objectives of the regional development policies are as follows:

- to reduce the existing regional disparities, especially by stimulating the wellbalanced development and the revitalization of the disadvantaged areas (lagging behind in development) and by preventing the emergence of new imbalances;

- to prepare the institutional framework in order to comply with the integration criteria into the EU structures and to ensure access to the financial assistance instruments (the Structural Funds and the Cohesion Fund of the EU);

- to correlate the governmental sector development policies and activities at the level of regions by stimulating the inter-regional, internal and international, cross-border cooperation which contributes to the economic development and is in accordance with the legal provisions and with the international agreements to which Romania is a party;

The principles that the elaboration and the application of the development policies are based on are:

- Decentralization of the decision making process, from the central/ governmental level to the level of regional communities;

- Partnership among all those involved in the area of regional development;

- Planning - utilization process of resources (through programs and projects) in view of attaining the established objectives;

Co-financing - the financial contribution of the different actors involved in the accomplishment of the regional development programs and projects.

\section{Cross Border Co-operation Programs in Romania}

As National Coordinator of the cross border co-operation programs, the Ministry of Development and Prognosis focuses on the involvement of the local actors representing the counties from the border region with Bulgaria and Hungary in the preparation of the projects proposed to be financed, and on the co-ordination between the local community needs and the provisions of the National Development Plan. According to the short, medium and long-term priorities 
agreed by the Joint Co-operation Committees established for the borders with Bulgaria and Hungary, project proposals in the following fields have been and will be financed from EU Phare funds:

- Improvement of the existing transport infrastructure on the Trans-European Corridors IV (Dresden - Constanta - Thesaloniki - Istanbul) and IX (Baltic Sea - Aegean Sea, on the sector Bucharest - Dimitrovgrad);

- Promotion of the environmental protection, especially water resources management;

- Free flow of persons, services and goods through the border crossing points;

- Socio-economic regional development through the Small Projects Fund.

Having in view the European Commission Regulation No. 2760/1998 already entered in force regarding the cross-border co-operation, at least $90 \%$ of the funds allocated per year for a border region will be used for major investment projects as follows: a min. of $2 \mathrm{M}$ Euro (Phare funds) plus $25 \%$ national cofinancing from the total investment value.

We would also like to mention that in accordance with the common agreements, both committees set-up with the Bulgarian and Hungarian partners decided to increase gradually, starting with the year 2000, the importance given to small scale projects by allocating more funds on annual basis, up to $10 \%$ from the total available/allocated funds (a max. of 800.000 Euro for the RomanianBulgarian border region and a max. of 500.000 Euro for the RomanianHungarian border region). These projects will be proposed exclusively by local actors within the Small Projects Fund.

Looking back on the achievements of the Phare cross-border cooperation programs and Phare Credo program in Romania for the period 1996-2000 in all the 18 counties from the border region with Hungary, Bulgaria, Moldova and Ukraine it was highlighted that the total amount of the Romanian project is in a total of $45.2 \mathrm{M}$ euro:

Phare funds: $29.2 \mathrm{M}$ Euro and national co-financing: $16 \mathrm{M}$ Euro, representing $35.5 \%$ from the total value of the projects.

For the next two years the following funds will be available for Romania: 
- $8 \mathrm{M}$ Euro for the counties from the Romanian-Bulgarian border region;

- $5 \mathrm{M}$ Euro for the counties from the Romanian-Hungarian border region

\section{Conclusion}

In the future, according to WTTC, the number of the foreign tourists will rise exponentially due to the joining of Romania with the European Union, and also because Romania is considered as an attractive country. However, growth should not make us myopic and sustainability should be ensured at all levels: both inter and intra-generational. Opportunities are challenges as well: the fruition of these opportunities is contingent upon how we meet the associated challenges. As responsible citizens and groups, we should:

- Prove and exemplify that sustainability issues offer one and the only means for developing truly sustainable international tourism.

- Frame guidelines for future negotiations in such a manner that when implemented, only sustainable use of touristic resources will result in profit. This is one of the best ways for trade liberalization efforts to regain the lost legitimacy.

- Ensure that the rounds of negotiations with EU are open to all legitimate parties, including governmental tourism bodies (NTOs) and their intergovernmental (IGOs) counterparts, destination and attraction owners, intermediaries, accessibility and amenity providers, representatives of the labor force, local communities at the destinations, NGOs, and other grassroots level organizations.

- Demand commitment and cooperation of suppliers of air, land, and maritime infrastructure, construction and management services, and other entities, in the sustainable development programs of international and regional organizations.

- Ensure that negotiations are not carried out in isolation and do not undermine concerted efforts in multiple forums to promote sustainable development, thereby preventing conflicting legal obligations for governments.

- Demand the establishment of local chapters within the EU organization with reasonable autonomy to take into account local priorities and concerns and incorporate them into a wider bottom-up framework. 
- Provide educational and training drives aimed at the developing world to enable or empower them to take advantage of increased open trade. Awareness programs in the areas of gender equitability and related issues should also be designed.

- Ensure that trade policy issues with EU do not impose themselves into other policy areas that are weaker and less market supported, but possibly better reflecting the essence of human culture.

- Lobby for a special annex on tourism since heterogeneity of the industry makes it virtually impossible to monitor progressive liberalization and its impacts. One probable solution is a cluster approach modifying the World Tourism Organization's Tourism Satellite Account (TSA). This will, in addition, not fundamentally thwart the 'negotiate as a package' requirement.

Contingent factor that might get in the way have the power to redirect the entire trajectory. Browsing literature across time might reveal to a discerning reader that the debates on sustainable tourism and its impacts have gone through a radical shift in the post September 11. Diverse conceptions of terms and their practical realizations in different communities, cultures and stakeholder groups can bound the scope of any dominant and consensual design among reactionary groups and in which case this Achilles' heel will be the greatest boon for the post colonial super states and their trans-national giants.

\section{References:}

1. Bausch, Th - Le Tourisme ef I'Environnement en Europe, Office des Publications Officielles des Communautés Européennes, Luxemburg, 2000

2. Dolipschi, M.O. - The Sustainable Development of Tourism, Simpozionul international al tinerilor cercetă tori, Academia de Studii Economice din Moldova, Editura A.S.E.M., Chişinău

3. Manning Ed., Dougherty D. T. - Sustainable Tourism, University Cornell, Montreal, 1995

4. Nedelea, Al. - Piała turistică, Ed. Didactică şi Pedagogică, Bucureşti, 2003

5. Nedelea, Al. - Politici de marketing în turism, Ed. Economică, Bucureşti, 2003

6. Stucki, E. - Le developpement équilibré du monde rurale en Europe, Sauvegarde de la nature, nr. $58 / 1992$

7. Watson, G. - Tourist Carring Capacity, Wiley, 1996

8. World Tourism Organization - The Least Developed Countries and International Tourism, Background Note presented at the High Level Meeting on Tourism in LDC, Canary Island, March 2001 